\title{
Comprehensive analysis of HE4 expression in normal and malignant human tissues
}

\author{
Mary T Galgano ${ }^{1}$, Garret M Hampton² and Henry F Frierson Jr \\ ${ }^{1}$ Department of Pathology, Robert E. Fechner Laboratory of Surgical Pathology, University of Virginia Medical \\ Center, Charlottesville, VA, USA and ${ }^{2}$ Genomics Institute of the Novartis Research Foundation, San Diego, \\ CA, USA
}

\begin{abstract}
The HE4 (WFDC2) gene encodes a WAP-type four disulphide core domain-containing protein with a presumptive role in natural immunity. Multiple studies have consistently identified upregulation of $H E 4$ gene expression in carcinomas of the ovary; however, the expression in normal and malignant adult tissues has not been examined in detail. Here, we examined the expression of the HE4 gene and protein in a large series of normal and malignant adult tissues by oligonucleotide microarray and tissue microarray, respectively. HE4 gene expression was highest in normal human trachea and salivary gland, and to a lesser extent, lung, prostate, pituitary gland, thyroid, and kidney. In a series of $\mathbf{1 7 5}$ human adult tumors, gene expression was highest in ovarian serous carcinomas. However, adenocarcinomas of the lung, and occasional breast, transitional cell and pancreatic carcinomas had moderate or high levels of HE4 expression. Using tissue microarrays and full tissue sections of normal and $\mathbf{4 4 8}$ neoplastic tissues, HE4 immunoreactivity was found in normal glandular epithelium of the female genital tract and breast, the epididymis and vas deferens, respiratory epithelium, distal renal tubules, colonic mucosa, and salivary glands, consistent with HE4 gene expression. In addition to consistent positivity in ovarian carcinoma, some pulmonary, endometrial, and breast adenocarcinomas, mesotheliomas, and less often, gastrointestinal, renal and transitional cell carcinomas were also positive. Knowledge of the expression patterns of HE4 in our survey is useful for application in histopathologic diagnosis, and should be taken into consideration in future studies that examine the role of HE4 as a serological tumor biomarker or as a target for gene-based therapy.

Modern Pathology (2006) 19, 847-853. doi:10.1038/modpathol.3800612; published online 7 April 2006
\end{abstract}

Keywords: HE4; immunohistochemistry; oligonucleotide microarray; ovarian carcinoma; tissue microarray; WFDC2

Human epididymis protein 4 (HE4) was first identified in the epithelium of the distal epididymis and originally predicted to be a protease inhibitor involved in sperm maturation. ${ }^{1,2}$ The gene, also known as WFDC2, encodes a protein with a WAPtype four disulphide core (WFDC) domain. ${ }^{3}$ Given its homology and comparable transcription profile with known leukocyte protease inhibitors in the WFDC family of proteins, HE4 also presumably has a role in natural immunity. ${ }^{3-5}$ In malignant neoplasms, gene expression profiling studies have consistently identified upregulation of $\mathrm{HE} 4$ in carcinomas of the ovary, ${ }^{6-14}$ and several studies have analyzed HE4 protein expression in ovarian neoplasms, providing the opportunity for its appli-

Correspondence: Dr HF Frierson Jr, MD, Department of Pathology, University of Virginia Medical Center, PO Box 800214, Charlottesville, VA 22908, USA

E-mail: hff@virginia.edu

Received 12 January 2006; revised and accepted 17 March 2006; published online 7 April 2006 cation in histopathologic diagnosis. ${ }^{12,13,15,16}$ Moreover, recent studies have shown elevated HE4 protein levels in serum from patients with ovarian tumors, demonstrating a similar sensitivity to CA125, but increased specificity for malignant tumors as compared to benign disease. ${ }^{17}$ However, the examination of HE4 in other common malignancies, benign lesions, and normal tissues has not occurred to a large scale. Here, we used oligonucleotide and tissue microarrays to survey HE4 gene and protein expression in a large group of malignant and normal tissues from adults. We discuss the implications of our results in terms of the potential role for HE4 in histopathologic diagnosis, as a serum tumor biomarker, and as a therapeutic target.

\section{Materials and methods}

Oligonucleotide Microarray

HE4 is one of more than 8900 different human genes represented on U95a GeneChips (Affymetrix, Santa 
Clara, CA, USA), which we used previously to develop a molecular classification of 175 human carcinomas based on patterns of gene expression. ${ }^{18}$ With the exception of the ovarian neoplasms, the same carcinomas analyzed for gene expression were also examined for HE4 by immunohistochemistry on tissue microarrays (see below). In brief, frozen sections of profiled tumors were examined by hematoxylin-and-eosin, and areas rich in neoplastic cells were cut from the frozen blocks. RNA extraction and hybridization onto oligonucleotide microarrays (U95a GeneChip; Affymetrix) were performed as reported previously. ${ }^{19}$ The processing and scaling of the hybridization data were also performed as described previously. ${ }^{20,21}$ Gene expression was quantitated in relative intensity units, and divided into three groups: low $(<300)$, moderate $(300-999)$ and high $(\geq 1000)$.

\section{Tissue Microarray}

The University of Virginia Human Investigation Committee approved the use of human tissues in this study. Tissue microarrays containing 1-3 0.6-mm cores from a comprehensive selection of formalin-fixed, paraffin-embedded normal tissues (Table 1) and neoplasms from adult patients (Table 2) were constructed using a tissue microarrayer (Beecher Instruments, Silver Spring, MD, USA). Selected whole tissue sections were stained for comparison with the tissue microarrays. In addition, whole tissue sections were used for most of the renal papillary and chromophobe carcinomas, oncocytomas, ovarian clear cell carcinomas, and basal cell carcinomas of the skin.

\section{Immunohistochemistry}

Formalin-fixed, paraffin-embedded sections were placed in citrate buffer ( $\mathrm{pH}$ 6.0) and heated in a microwave oven for 20 min before application of the rabbit polyclonal antibody to HE4 (1:20 dilution; Signet Laboratories Inc., Dedham, MA, USA). After incubation with the primary antibody, and addition of the biotinylated secondary antibody, avidinbiotin immunoperoxidase was applied. Diaminobenzidine was used as the chromogen. Sections were then counterstained with hematoxylin. Tissue sections of human epididymis processed in a comparable manner provided a positive control with surrounding soft tissue providing an internal negative control. Immunoreactivity was evaluated independently by two observers without specific knowledge of the oligonucleotide microarray results. Cytoplasmic staining was graded for intensity (0-negative, 1-weak, 2-moderate, and 3-strong) and percentage of positive cells $(0,1(1-24 \%), 2$ (25$49 \%), 3(50-74 \%)$, and $4(75-100 \%))$ with discrepancies resolved by consensus. The grades were multiplied to determine an $\mathrm{H}$-score. The $\mathrm{H}$-scores
Table 1 Normal tissues examined for HE4 by immunohistochemistry

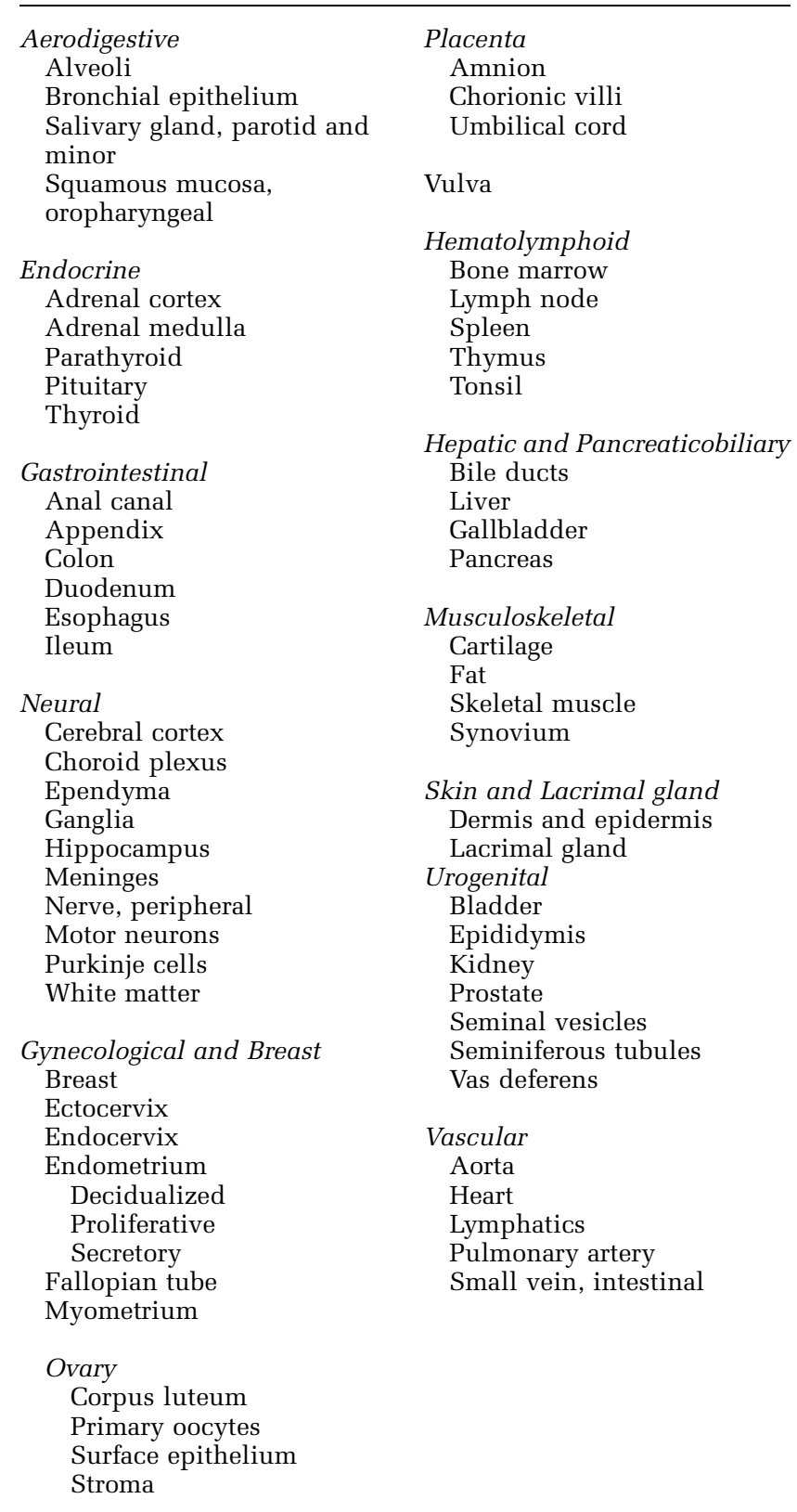

for tumors with multiple cores were averaged. Protein expression was then defined as negative $(\mathrm{H}$-score $=0)$, weak $(\mathrm{H}$-score $=1-3)$, or strong $(\mathrm{H}-$ score $\geq 4)$.

\section{Results}

\section{Oligonucleotide Microarray Analysis}

Among a series of 43 normal human tissues previously reported, ${ }^{22}$ expression of $\mathrm{HE} 4$ was restricted, with highest levels in trachea and salivary gland and to a lesser extent in lung, prostate, thyroid, pituitary gland and kidney (data not shown; 
Table 2 Neoplasms stained for HE4

\begin{tabular}{|c|c|c|c|}
\hline & Negative & Weak & Strong \\
\hline $\begin{array}{l}\text { Bladder and ureter, transitional } \\
\text { cell carcinoma }\end{array}$ & 23 & 7 & 2 \\
\hline Breast, invasive ductal carcinoma & 14 & 9 & 3 \\
\hline $\begin{array}{l}\text { Endometrial carcinoma, endometrioid } \\
\text { type }\end{array}$ & 2 & 3 & 11 \\
\hline \multicolumn{4}{|c|}{ Gastrointestinal, hepatic, pancreaticobiliary } \\
\hline Colorectal carcinoma & 21 & 6 & 0 \\
\hline Hepatocellular carcinoma & 5 & 0 & 0 \\
\hline Pancreaticobiliary carcinoma & 1 & 3 & 4 \\
\hline Upper gastrointestinal carcinoma & 15 & 2 & 0 \\
\hline \multicolumn{4}{|l|}{ Kidney } \\
\hline Renal cell carcinoma, clear cell type & 25 & 1 & 0 \\
\hline Renal cell carcinoma, papillary type & 7 & 1 & 5 \\
\hline Chromophobe carcinoma & 4 & 5 & 4 \\
\hline Oncocytoma & 4 & 3 & 5 \\
\hline \multicolumn{4}{|l|}{ Lung } \\
\hline Adenocarcinoma & 9 & 5 & 7 \\
\hline Squamous cell carcinoma & 6 & 3 & 0 \\
\hline \multicolumn{4}{|l|}{ Mesothelioma } \\
\hline Epithelioid type & 12 & 8 & 8 \\
\hline Spindle cell type & 7 & 3 & 9 \\
\hline \multicolumn{4}{|l|}{ Ovary } \\
\hline Serous papillary carcinoma & 0 & 6 & 26 \\
\hline Endometrioid carcinoma & 2 & 3 & 5 \\
\hline Clear cell carcinoma & 2 & 2 & 9 \\
\hline Poorly differentiated carcinoma & 0 & 3 & 1 \\
\hline Mucinous tumor & 6 & 1 & 0 \\
\hline Germ cell tumor & 5 & 0 & 0 \\
\hline Sex cord stromal tumor & 9 & 0 & 0 \\
\hline Gastrointestinal metastasis & 1 & 3 & 1 \\
\hline Prostatic adenocarcinoma & 20 & 0 & 0 \\
\hline Salivary gland, various & 0 & 12 & 12 \\
\hline Skin, basal cell carcinoma & 10 & 1 & 0 \\
\hline Thyroid, various & 13 & 12 & 10 \\
\hline
\end{tabular}

see http://symatlas.gnf.org). In malignant tissues, the highest expression levels were observed in serous ovarian carcinomas $(N=26)$ (Figure 1). High expression was also noted in nine of 13 adenocarcinomas of the lung and a single squamous cell carcinoma; the remainder of squamous lung tumors (12 of 13) had moderate or low levels of expression. High expression was detected in two of eight transitional cell carcinomas of the urinary tract, while only a single renal cell carcinoma (clear cell type) demonstrated high expression $(N=11)$. Twenty of 27 invasive ductal carcinomas of the breast had low levels of HE4 expression, with occasional tumors demonstrating high levels of expression. Eighteen of 23 colon carcinomas had low expression, while five of 12 gastric adenocarcinomas had moderate expression levels. Four of six pancreatic adenocarcinomas had moderate expression, and one had a high level of HE4 expression. Hepatocellular carcinomas $(N=7)$ had low expression. Prostate adenocarcinomas occasionally had moderate $H E 4$ expression (five of 26).

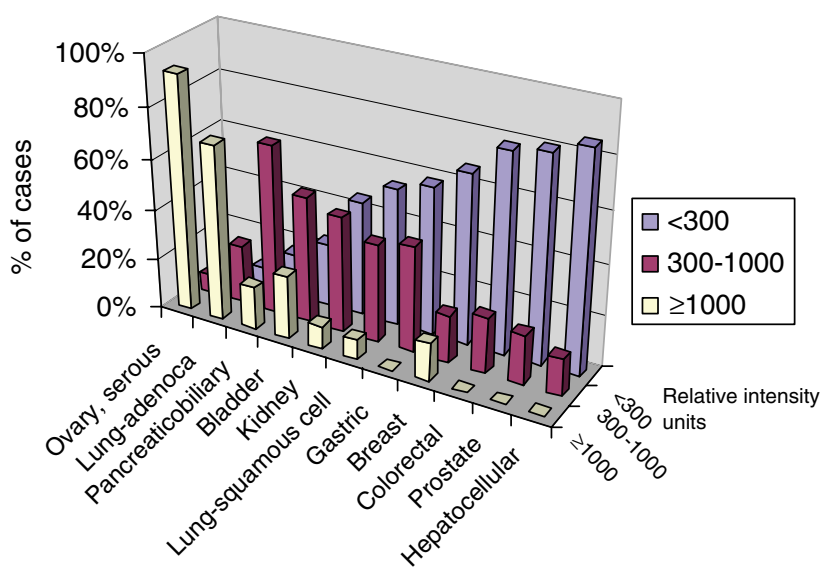

Figure 1 HE4 gene expression in 175 human carcinomas. Levels of mRNA expression were determined by hybridization to Affymetrix U95a GeneChips. Relative fluorescence units were divided into three groups: low $(<300)$, moderate $(300-1000)$, and high $(\geq 1000)$.

\section{Immunohistochemistry of Normal Adult Tissues}

Immunohistochemical staining for HE4, when present, was limited to epithelium. It was detected in the normal epithelium of the female genital tract, including endocervical glands, endometrial glands, fallopian tube, and Bartholin's glands. Breast epithelium was variably positive, but typically stronger in the ducts than in the lobules. We observed very rare focal staining within the epithelium of the prostate gland. The epithelium of the vas deferens was also positive. There was strong staining within the distal convoluted tubules of the kidney, with equivocal staining of the proximal convoluted tubules, likely non-specific uptake. Bronchial epithelium was immunoreactive. Both minor and major salivary glands demonstrated strong staining of the ductal epithelium, consistent with the high levels of gene expression, with weaker and focal staining of the acinar cells. Scattered cells in the anterior pituitary gland were strongly positive. Oxyphilic thyrocytes were weakly positive. We observed focal staining within the lacrimal gland, and weak staining within eccrine glands. Colonic epithelium was variably positive, while rare pancreatic acinar cells were weakly immunoreactive. The remaining tissues examined (Table 1) lacked immunoreactivity for HE4.

\section{Immunohistochemistry of Neoplasms}

Staining for HE4 in 448 neoplasms is summarized in Table 2. Of ovarian tumors (Figure 2), all serous $(N=32)$, including two borderline tumors, and all poorly differentiated $(N=4)$ ovarian carcinomas were positive (Figure 3a), but with intratumoral variability, confirmed by selected immunostaining of standard tissue sections. Endometrioid carcinomas $(N=10)$ and clear cell carcinomas $(N=13)$ were 
mostly positive, while mucinous carcinomas were negative (except for one that stained weakly). Granulosa cell tumors $(N=5)$, fibromas $(N=4)$, dysgerminomas $(N=4)$, and a single yolk sac tumor were negative for HE4. All four metastatic colorectal tumors showed some positivity, while a single metastatic gastric carcinoma was negative.

Staining for HE4 in non-ovarian neoplasms is summarized in Figure 4. Nearly $90 \%$ of endometrial

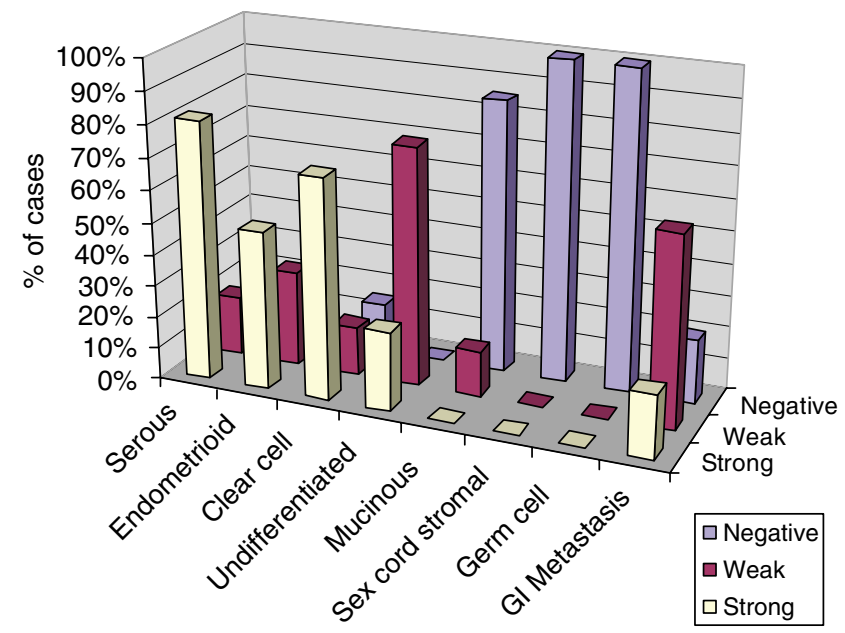

Figure 2 HE4 immunoreactivity in tissue microarrays of ovarian tumors. Degree of staining was scored as negative $(\mathrm{H}$-score $=0)$, weak $(\mathrm{H}$-score $=1-3)$, or strong $(\mathrm{H}$-score $\geq 4)$. carcinomas, endometrioid type, were positive for HE4. Breast carcinomas showed variable expression, as 14 were negative, nine were weakly positive, and three were strongly positive (Figure $3 \mathrm{~b}$ ). All prostate carcinomas were negative, while nine of 32 transitional cell carcinomas showed some immunoreactivity. Only one of 26 renal cell carcinomas, clear cell type, was positive, while five of 13 papillary renal cell carcinomas demonstrated strong

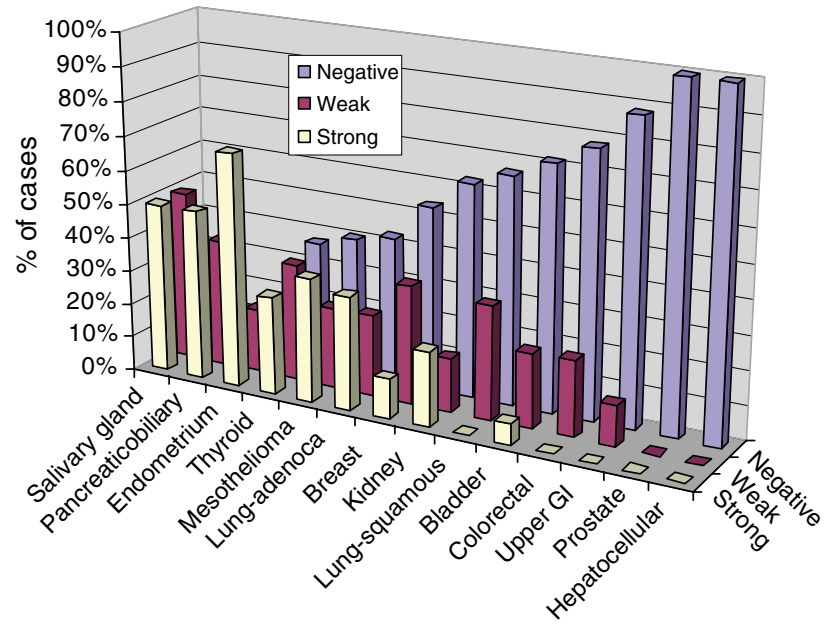

Figure 4 HE4 immunoreactivity in tissue microarrays of nonovarian tumors. Degree of staining was scored as negative $(\mathrm{H}$-score $=0)$, weak (H-score $=1-3)$, or strong $(\mathrm{H}$-score $\geq 4)$.
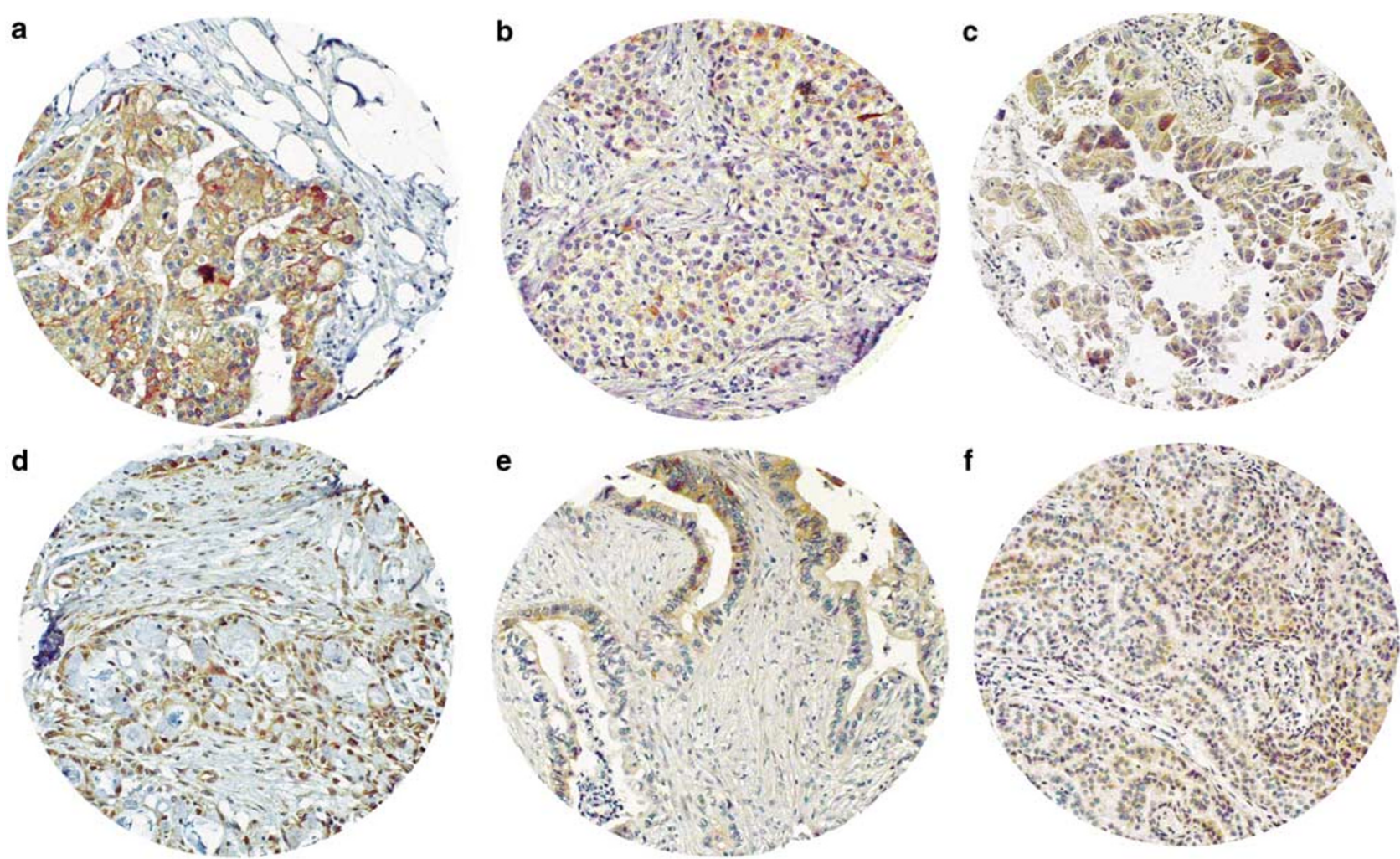

Figure 3 Examples of HE4 immunoreactivity in tissue microarrays of (a) ovarian serous carcinoma, (b) invasive ductal carcinoma of the breast, (c) adenocarcinoma of the lung, (d) mucoepidermoid carcinoma, (e) pancreatic carcinoma, and (f) epithelioid malignant mesothelioma. 
immunoreactivity. Of 13 chromophobe carcinomas, four were strongly positive, with weak staining in an additional five cases. Oncocytomas showed similar staining, with strong immunoreactivity in five cases, weak in three, and no staining in four tumors.

Twelve of 21 adenocarcinomas of the lung (Figure 3c) were positive while three of nine squamous cell carcinomas were weakly positive for HE4. All salivary gland neoplasms demonstrated some reactivity. Prominent staining was identified in the epithelium of Warthin's tumors $(N=7)$ and in two mucoepidermoid carcinomas (Figure 3d), while variable staining was seen in mixed tumors $(N=5)$ and salivary duct carcinomas $(N=2)$. Focal, weak staining occurred in adenoid cystic carcinomas $(N=7)$ and a single polymorphous low-grade adenocarcinoma.

Colorectal (six of 27) and upper gastrointestinal tract (two of 17) adenocarcinomas occassionally demonstrated weak positivity. All hepatocellular carcinomas were negative, while five of six pancreatic carcinomas (Figure 3e), a single gallbladder carcinoma, and a single cholangiocarcinoma were immunoreactive. Of thyroid carcinomas, immunopositivity was observed in 10 of 13 papillary and nine of 13 follicular carcinomas. No reactivity was found in an anaplastic, and two medullary carcinomas. Three of the six follicular adenomas were also positive. Positive staining was present in 12 of 19 spindle cell and 16 of 28 epithelioid malignant mesotheliomas (Figure 3f). Ten of 11 basal cell carcinomas lacked immunoreactivity. A single pituitary adenoma (GH secreting) was also negative.

\section{Discussion}

HE4 (WFDC2) is one of 14 homologous genes on chromosome 20q12-13.1 which encode proteins with a WAP-type four disulphide core (WFDC) domain. $^{3}$ Two of these genes, SLPI and elafin, encode known leukocyte protease inhibitors ${ }^{23,24}$ which are co-expressed with HE4 in the upper aerodigestive, reproductive, and urological tracts. ${ }^{4}$ The genes at the WFDC locus are variably conserved across species, and presumably share a role in natural immunity with both antimicrobial and anti-inflammatory activity. ${ }^{5}$ Expression of SLPI and elafin has been identified in various carcinomas, and these genes may play a role in cancer development or progression. ${ }^{25-29}$ In addition, amplification of 20q12-13 has been demonstrated specifically in breast and ovarian carcinomas. ${ }^{30,31}$

Recent interest in HE4 has been generated by the consistent demonstration of overexpression in ovarian carcinomas in comparison to normal ovarian tissue. Although a meta-analysis of gene expression profiles of ovarian carcinomas found HE4 to be the most frequently upregulated gene, ${ }^{32}$ a large scale evaluation of $\mathrm{HE} 4$ gene and protein expression in both normal tissues and common nonovarian carcinomas has not been performed thus far.

We found that ovarian serous carcinomas had, on average, considerably higher levels of HE4 gene expression than other carcinomas. Adenocarcinomas of the lung demonstrated the next highest average level of intensity, while squamous cell carcinomas had low expression levels. Transitional cell, breast, renal, and pancreatic carcinomas had moderate levels of HE4 expression, but several of them had comparable levels to that for serous ovarian carcinomas. Colonic, gastric, hepatic and prostatic carcinomas had mostly low levels of $H E 4$ expression.

In our study, we found evidence of HE4 protein in the normal glandular epithelium of the female genital tract, while the normal ovarian surface epithelium was negative. In the male genital tract, only the epididymis and vas deferens were strongly immunopositive. Elsewhere, respiratory epithelium, distal renal tubules, and salivary glands were also consistently immunoreactive. Colonic mucosa was positive with variable intensity.

In agreement with other studies, ${ }^{12,13,15,16}$ most of the ovarian surface epithelial tumors, with the exception of mucinous type, were immunoreactive for HE4. Significant staining was also identified in endometrial, lung, breast, and pancreaticobiliary carcinomas, as well as various renal, thyroid and salivary gland neoplasms, and malignant mesotheliomas.

Our immunohistochemical and oligonucleotide microarray results show that while upregulation of HE4 in ovarian serous tumors is considerably higher than that of other carcinomas, occasional nonovarian tumors achieve similar levels of protein and mRNA expression. As HE4 can be detected by immunohistochemistry in a variety of common carcinomas that may be in the differential diagnosis of ovarian cancer, an anti-HE4 antibody obviously should not be used in isolation, but may complement the selection of other antibodies for diagnosis. Although HE4 was consistently expressed in serous, poorly differentiated, and endometrioid-type carcinomas, the staining was sometimes variable, and therefore a lack of staining in a limited biopsy sample should be interpreted with caution. While most of the cancers positive for HE4 showed diffuse cytoplasmic staining, rare adenocarcinomas contained cells with prominent apical accentuation.

In addition to its potential utility in histopathologic diagnosis, HE4 has been analyzed as a serological biomarker for ovarian carcinoma. In a report using a HE4-based ELISA assay tested in women with benign or malignant ovarian disease as well as in age-matched controls, HE4 showed comparable sensitivity to CA125, but had better specificity for malignant tumors. ${ }^{17}$ Based on our results, further serological evaluation should include patients with a variety of benign and malignant diseases of other major organs, including lung, 
thyroid, salivary gland, pancreas, endometrium, breast, urothelium, and mesothelium.

Given the identification of an HE4 promoter which is differentially active in ovarian cancer cell lines as compared to normal controls, transcriptional targeting for gene-based therapy remains an area of active investigation. ${ }^{33}$ Similar studies have evaluated the use of the promoter for the WFDC family member SLPI for gene therapy in ovarian and cervical carcinomas. ${ }^{34-36}$

In summary, our results characterize the distribution of HE4 in normal adult tissues and various malignancies. We found significant gene expression and strong immunoreactivity in some pulmonary, endometrial, and breast adenocarcinomas, and less often, in gastrointestinal and urological carcinomas. Additionally, we noted the intratumoral variability of staining within ovarian serous carcinomas. Knowledge of the protein expression patterns of HE4 in our survey of carcinomas is useful for its application in histopathologic diagnosis, and should be taken into consideration in future studies that examine the role of HE4 as a serological tumor biomarker or as a target for gene-based therapy.

\section{Acknowledgements}

This work was funded in part by the UVA Pathology Resident Research Support Program. We thank Sharon Birdsall for her technical assistance.

\section{Duality of interest}

None declared.

\section{References}

1 Kirchhoff C, Habben I, Ivell R, et al. A major human epididymis-specific cDNA encodes a protein with sequence homology to extracellular proteinase inhibitors. Biol Reprod 1991;45:350-357.

2 Kirchhoff C. Molecular characterization of epididymal proteins. Rev Reprod 1998;3:86-95.

3 Clauss A, Lilja H, Lundwall A. A locus on human chromosome 20 contains several genes expressing protease inhibitor domains with homology to whey acidic protein. Biochem J 2002;368:233-242.

4 Bingle L, Singleton V, Bingle CD. The putative ovarian tumour marker gene HE4 (WFDC2), is expressed in normal tissues and undergoes complex alternative splicing to yield multiple protein isoforms. Oncogene 2002;21:2768-2773.

5 Clauss A, Lilja H, Lundwall A. The evolution of a genetic locus encoding small serine proteinase inhibitors. Biochem Biophys Res Commun 2005;333: 383-389.

6 Wang K, Gan L, Jeffery E, et al. Monitoring gene expression profile changes in ovarian carcinomas using cDNA microarray. Gene 1999;229:101-108.
7 Schummer M, Ng WV, Bumgarner RE, et al. Comparative hybridization of an array of 21,500 ovarian cDNAs for the discovery of genes overexpressed in ovarian carcinomas. Gene 1999;238:375-385.

8 Hough CD, Sherman-Baust CA, Pizer ES, et al. Largescale serial analysis of gene expression reveals genes differentially expressed in ovarian cancer. Cancer Res 2000;60:6281-6287.

9 Ono K, Tanaka T, Tsunoda T, et al. Identification by cDNA microarray of genes involved in ovarian carcinogenesis. Cancer Res 2000;60:5007-5011.

10 Welsh JB, Zarrinkar PP, Sapinoso LM, et al. Analysis of gene expression profiles in normal and neoplastic ovarian tissue samples identifies candidate molecular markers of epithelial ovarian cancer. Proc Natl Acad Sci USA 2001;98:1176-1181.

11 Shridhar V, Lee J, Pandita A, et al. Genetic analysis of early- vs late-stage ovarian tumors. Cancer Res 2001; 61:5895-5904.

12 Schaner ME, Ross DT, Ciaravino G, et al. Gene expression patterns in ovarian carcinomas. Mol Biol Cell 2003;14:4376-4386.

$13 \mathrm{Lu} \mathrm{KH}$, Patterson AP, Wang L, et al. Selection of potential markers for epithelial ovarian cancer with gene expression arrays and recursive descent partition analysis. Clin Cancer Res 2004;10:3291-3300.

14 Gilks CB, Vanderhyden BC, Zhu S, et al. Distinction between serous tumors of low malignant potential and serous carcinomas based on global mRNA expression profiling. Gynecol Oncol 2005;96:684-694.

15 Drapkin R, von Horsten $\mathrm{HH}$, Lin Y, et al. Human epididymis protein 4 (HE4) is a secreted glycoprotein that is overexpressed by serous and endometrioid ovarian carcinomas. Cancer Res 2005;65:2162-2169.

16 Rosen DG, Wang L, Atkinson JN, et al. Potential markers that complement expression of CA125 in epithelial ovarian cancer. Gynecol Oncol 2005;99: 267-277.

17 Hellstrom I, Raycraft J, Hayden-Ledbetter M, et al. The HE4 (WFDC2) protein is a biomarker for ovarian carcinoma. Cancer Res 2003;63:3695-3700.

$18 \mathrm{Su}$ AI, Welsh JB, Sapinoso LM, et al. Molecular classification of human carcinomas by use of gene expression signatures. Cancer Res 2001;61:7388-7393.

19 Welsh JB, Sapinoso LM, Su AI, et al. Analysis of gene expression identifies candidate markers and pharmacological targets in prostate cancer. Cancer Res 2001;61:5974-5978.

20 Lockhart DJ, Dong H, Byrne MC, et al. Expression monitoring by hybridization to high-density oligonucleotide arrays. Nat Biotechnol 1996;14: 1675-1680.

21 Wodicka L, Dong H, Mittmann M, et al. Genome-wide expression monitoring in Saccharomyces cerevisiae. Nat Biotechnol 1997;15:1359-1367.

$22 \mathrm{Su}$ AI, Cooke MP, Ching KA, et al. Large-scale analysis of the human and mouse transcriptomes. Proc Natl Acad Sci USA 2002;99:4465-4470.

23 Thompson RC, Ohlsson K. Isolation, properties, and complete amino acid sequence of human secretory leukocyte protease inhibitor, a potent inhibitor of leukocyte elastase. Proc Natl Acad Sci USA 1986; 83:6692-6696.

24 Wiedow O, Schroder JM, Gregory H, et al. Elafin: an elastase-specific inhibitor of human skin. Purification, characterization, and complete amino acid sequence. J Biol Chem 1990;265:14791-14795. 
25 Devoogdt N, Hassanzadeh Ghassabeh G, Zhang J, et al. Secretory leukocyte protease inhibitor promotes the tumorigenic and metastatic potential of cancer cells. Proc Natl Acad Sci USA 2003;100:5778-5782.

26 Devoogdt N, Revets H, Ghassabeh GH, et al. Secretory leukocyte protease inhibitor in cancer development. Ann NY Acad Sci 2004;1028:380-389.

27 Tian X, Shigemasa K, Hirata E, et al. Expression of human kallikrein 7 (hK7/SCCE) and its inhibitor antileukoprotease (ALP/SLPI) in uterine endocervical glands and in cervical adenocarcinomas. Oncol Rep 2004;12:1001-1006.

28 Robinson PA, Markham AF, Schalkwijk J, et al. Increased elafin expression in cystic, dysplastic and neoplastic oral tissues. J Oral Pathol Med 1996;25:135-139.

29 Zhang M, Zou Z, Maass N, et al. Differential expression of elafin in human normal mammary epithelial cells and carcinomas is regulated at the transcriptional level. Cancer Res 1995;55:2537-2541.

30 Tanner MM, Grenman S, Koul A, et al. Frequent amplification of chromosomal region 20q12-q13 in ovarian cancer. Clin Cancer Res 2000;6:1833-1839.

31 Larramendy ML, Lushnikova T, Bjorkqvist AM, et al. Comparative genomic hybridization reveals complex genetic changes in primary breast cancer tumors and their cell lines. Cancer Genet Cytogenet 2000;119: 132-138.

32 Israeli O, Goldring-Aviram A, Rienstein S, et al. In silico chromosomal clustering of genes displaying altered expression patterns in ovarian cancer. Cancer Genet Cytogenet 2005;160:35-42.

33 Berry NB, Cho YM, Harrington MA, et al. Transcriptional targeting in ovarian cancer cells using the human epididymis protein 4 promoter. Gynecologic Oncol 2004;92:896-904.

34 Barker SD, Coolidge CJ, Kanerva A, et al. The secretory leukoprotease inhibitor (SLPI) promoter for ovarian cancer gene therapy. J Gene Med 2003;5:300-310.

35 Barker SD, Dmitriev IP, Nettelbeck DM, et al. Combined transcriptional and transductional targeting improves the specificity and efficacy of adenoviral gene delivery to ovarian carcinoma. Gene Therapy 2003;10:1198-1204.

36 Robertson III MW, Wang M, Siegal GP, et al. Use of a tissue-specific promoter for targeted expression of the herpes simplex virus thymidine kinase gene in cervical carcinoma cells. Cancer Gene Ther 1998;5: 331-336. 